\title{
Peregrinación y comunión en De la tierra sin fuegos de Juan Pablo Riveros
}

\author{
Pilgrimage and communion in Juan Pablo Riveros \\ De la tierra sin fuegos \\ LUIS TORRES D. \\ "Professor of Spanish, Department of French, Italian and Spanish, \\ Faculty of Arts, University of Calgary \\ $\bowtie$ latorres@ucalgary.ca
}

\begin{abstract}
RESUMEN
Este estudio sobre De la tierra sin fuegos intenta elucidar algunas de las claves del acercamiento poético hacia tres culturas australes: los Selk’nam, Yámana y Kawésqar. Proponemos que Riveros crea una ficción del viaje hacia la otredad e imagina al viajero en la figura del etnólogo Martín Gusinde. El viaje supone un recorrido por el archivo fueguino y es transformado en una peregrinación que culmina en la comunión. La vuelta al pasado hace patente la repetición de las atrocidades: el exterminio de los fueguinos y la violencia de la dictadura militar durante el período de la escritura del libro.
\end{abstract}

Palabras clave: Viaje poético, archivo, peregrinación, comunión.

\begin{abstract}
This article, dealing with De la tierra sin fuegos, attempts to elucidate some of the main ideas concerning the poetical encounter with three cultures of the austral region of South America: the Selk'nam, Yámana and Kawésqar. We propose that Riveros creates a fiction of the journey towards the other and imagines the traveler in the image of the ethnologist Martin Gusinde. The journey implies a passing through the Fueguian archive and it becomes a pilgrimage which culminates in an act of communion. The return to the past brings forth the manner in which atrocities continue to be repeated: the extermination of the Fueguian peoples and the military violence during the time the book was written.
\end{abstract}

Key words: Poetic journey, archive, pilgrimage, communion. 
La representación del viaje hacia los territorios indígenas y la descripción del contacto entre las culturas europeas y locales se ha basado principalmente en una dicotomía que define a los pueblos autóctonos en un sentido negativo, al mismo tiempo que privilegia con cualidades positivas, relacionadas con una supuesta superioridad cultural, al sujeto activo del proyecto colonizador: el viajero. De la tierra sin fuegos (1986)르. obra poética publicada en Concepción, Chile, es un libro que trastorna esa dicotomía, además que subvierte el ensamblaje discursivo sobre el cual han sido construidas las imágenes de los grupos nativos en nuestra cultura. Reaccionando contra el olvido y con el propósito de establecer nuevas conexiones entre las experiencias de la comunidad indígena y el presente de la escritura, Riveros convoca, en el espacio imaginante de la poesía, la presencia de tres antiguos pueblos del extremo sur del continente americano: los Selk’nam (Ona), Yámana (Yagán) y Kawésqar (Alacalufe), quienes fueron exterminados por la negligencia cómplice del estado chileno y argentino, y por la intervención de colonos europeos a fines del siglo XIX y a principios del siglo XX.

En De la tierra sin fuegos la crítica de las representaciones de los pueblos originarios ocurre en dos planos: por una parte, el poeta abre el archivo fueguino y convierte la lectura y la interpretación en una especie de viaje por las diferentes posiciones ideológicas que orientaban los documentos relacionados con las culturas australes. Por otra parte, a nivel de la experiencia en el mundo proyectado en los poemas, el autor desestabiliza los supuestos tradicionales del acercamiento y del encuentro intercultural al transformar el viaje en una peregrinación poética hacia los habitantes fueguinos y sus territorios. Más adelante, veremos que la peregrinación y la relación crítica con los documentos abren cauce a representaciones alternativas de la otredad y llevan a un estado más profundo, aunque no idealizado, de comunión entre el viajero y la cultura local.

En 1986, fecha de la publicación, su escritura era un proyecto difícil, por la amplitud de los temas y por las dificultades que presentaba la publicación del libro. Con todo, Riveros desarrolla una reflexión sobre el pasado en la peregrinación y la expande al presente, pues enfrenta su propio momento histórico que estaba determinado por la represión política que sufría la sociedad chilena bajo la dictadura militar en los años ochenta. Así pues, la obra de este poeta constituye un esfuerzo por recuperar las memorias censuradas y por rehacer éticamente la presencia indígena en un espacio de lucha por la reconstrucción de la cultura democrática.

A lo largo del libro, lo que llamamos el viaje por el archivo está estructurado en torno a una serie de referencias al contacto, colonización y exterminio de los fueguinos. Estas alusiones se bifurcan en torno a dos posiciones: de un lado, encontramos citas y menciones a documentos cuya ideología expansionista y colonial dio legitimidad a la explotación y destrucción de las culturas australes. De otro lado, y desde los márgenes de esa documentación, Riveros rescata una posición alternativa, opuesta a la deshumanización de lo indígena, que halla en el testimonio del etnólogo alemán Martin Gusinde, autor del estudio Die Feuerland Indianer

Para este ensayo, sigo la primera edición; la segunda fue publicada en el año 2001 por Cosmigonon Ediciones, Concepción, Chile. 
(1931-1974) y del más breve y popular ensayo, Hombres primitivos en la Tierra del Fuego (de investigador a compañero de tribu) (1951). Gusinde y Joseph Emperaire, un estudioso francés que escribió Los nómades del mar (1963), sobre la cultura Kawésqar, son dos importantes investigadores que hicieron pública su crítica de la violencia expansionista y de la política de exterminio que promovían los gobiernos y colonos en contra de los habitantes de la Tierra del Fuego y de las islas australes ${ }^{2}$. En sus poemas, Riveros evoca la imagen de Gusinde y sus escritos, junto a los de Emperaire, le sirven de referentes para la construcción del encuentro poético con los pueblos desaparecidos.

Hay que recalcar, en breve, que este trabajo de Riveros participa de una larga tradición de libros que tratan del acercamiento intercultural y que, en su mayoría, observan el mundo indígena desde la perspectiva europea. Aunque en los poemas no hay alusiones directas a esa tradición, no se menciona a Colón o Ercilla, por ejemplo, es claro que por su temática y por su posición alternativa respecto al viaje y al contacto, el poeta está en diálogo con esos y otros antecesores más recientes. En los años que siguen a la publicación de Riveros, su inquietud por las culturas del sur del continente americano pasa a ser compartida en otras obras chilenas. Entre ellas destacan los escritos de Astrid Fugellie en Los círculos (1988), algunas pinturas de Eugenio Dittborn, la composición musical del grupo Congreso, Los fuegos del hielo. Música para ballet (1992), y el libro Tierra de humo. Imágenes fotográficas 1882/1950 publicado por la editorial LOM y el Museo de Arte Precolombino en 1994. Las novelas Mi pobre tercer deseo (1990) de Agata Giglio y El corazón a contraluz (1996) de Patricio Manns son otras dos contribuciones importantes para la recuperación poética del mundo fueguino y para el reconocimiento de la continuidad histórica ante la corriente del olvido en el Chile de los noventa y en lo que va del nuevo milenio.

En este ensayo nos proponemos estudiar tres aspectos del encuentro intercultural imaginado en De la tierra sin fuegos: 1) veremos algunas de las características de la representación de los pueblos indígenas y la subversión que logra Riveros en el recorrido por el archivo; 2) revisaremos la peregrinación poética, una forma de acercamiento a las culturas locales que subvierte la tradición del viaje de conquista o la expedición civilizadora. En la peregrinación son importantes dos aspectos de la "praxis" del viaje: el acto del viaje, donde se lleva a cabo el cruce de instancias "liminales" que transforman al viajero y que trastornan las relaciones tradicionales del viaje expedicionario; y, junto a esto, el vínculo con otros, es decir, la praxis en la "relación cara a cara" que sustenta la vida en comunidad. En este lugar, seguimos la definición de praxis que ofrece Enrique Dussel en su libro Ethics and Community (1988). Praxis, para Dussel, es acción y vínculo, dos ideas que relacionamos con las de peregrinación y comunidad, respectivamente; 3) por último, nos concentraremos en las imágenes de la comunión. Veremos, luego, que éstas se manifiestan en dos planos que

Esta actitud crítica queda manifiesta en Hombres primitivos..., donde Martin Gusinde denuncia las atrocidades cometidas por "el hombre blanco civilizado" (p. 97) en la Patagonia:

Ha avasallado con desenfrenada violencia los más sagrados derechos humanos. Ninguna fiera se ha comportado de manera tan cruel como lo han hecho los blancos contra los indios indefensos. Estos renglones deben ser una permanente protesta contra aquellos cazadores de hombres, que han aniquilado sin compasión al pueblo de Selk'nam (p. 97). 
corresponden a la "espiritualización-caspi" del extranjero, Gusinde, y a su transformación en miembro de la tribu (“caspi”, afirma Riveros, es una palabra Selk’nam que significa espíritu o alma).

Para abordar las nociones de peregrinación, liminalidad, comunidad y comunión, nos ayudamos de los trabajos de Victor Turner; en especial nos interesan sus aproximaciones etnológicas a la liminalidad de la peregrinación y a la creación de un nuevo tipo de comunidad o "communitas" en esta forma del viaje. Asimismo, por la influencia del pensamiento de Martin Gusinde y de Thomas Merton en el libro de Riveros, creemos que es apropiado considerar el trasfondo teológico de estas palabras. Seguimos la definición de peregrinación que propone Merton y nos apoyamos, según hemos dicho, en la obra del filósofo Enrique Dussel. Una perspectiva central de nuestra propuesta de estudio es que los poemas de Riveros realizan una adaptación rebelde y liberadora de la peregrinación, de la comunidad y la comunión, postura crítica que le permite delinear una nueva aproximación para representar el acercamiento y el encuentro con los pueblos australes. A través de estas nociones, Riveros consigue develar las mediaciones ideológicas que sustentaban la deshumanización de los fueguinos y promueve la recuperación de la dignidad humana perdida en esos discursos. Es, en concreto, en la comunión material y espiritual, es decir, en una ética de la memoria y de la lucha por el acercamiento al otro, que el autor pone en práctica la reflexión sobre la tragedia que une a los dos tiempos.

\section{EL VIAJE POR EL ARCHIVO}

Con el propósito de pluralizar el acercamiento ficcional e impulsar la crítica del archivo, Riveros imagina el viaje a la manera de un recorrido por una variedad de documentos que promovían imágenes generalmente negativas de los distintos grupos fueguinos. Esta "base intertextual” (1992, p. 181), título que Mauricio Ostria le da al conjunto de referencias que despliega el poemario y que forma los parámetros del viaje por el archivo, está apoyada en un aparato documental de textos referidos, citados o parafraseados: documentos históricos, diarios de viaje, estudios etnológicos, crónicas oficiales, cartas y poemas. Además, el libro contiene un importante cuerpo paratextual que documenta los datos entregados en el conjunto poético, incluyendo una colección de fotografías de la época (primeras décadas del siglo XX), notas aclaratorias, información bibliográfica y un glosario de palabras. Todos estos materiales, escritos y visuales, configuran un discurso híbrido que sobrepasa los marcos de lo puramente poético al dar espacio a lo documental. De igual forma, este discurso pone en escena una serie de registros verbales e ideológicos en conflicto, entre estos, los reportajes de viajeros y colonos y, en contraste con estos, los documentos que denunciaron las falsificaciones que promovían esos escritos.

La mayoría de los poemas están estructurados en torno a enunciados contrastantes, 
en los cuales es cuestionada la actitud dominante que tiende a denigrar a los indígenas sureños. Riveros identifica esos documentos, los cita y los hace objeto de una crítica que hace pública sus fundamentos deshumanizantes: las del llamado proyecto civilizador del mercantilismo en el siglo XIX y del modelo neoliberal en el presente de la escritura del libro. Consideremos, para enfocar, "Exterminio ona (1875-1905)" y "Dawson", dos poemas que unen lo poético con lo documental y que hacen explícito el valor de la continuidad temporal presente en el conjunto. "Exterminio ona (1875-1905)" contiene varias citas relacionados con la "colonización" de los fueguinos. Una de ellas refiere a un periódico inglés de la época:

THE DAILY NEWS, INGLATERRA, 1872:

"Indudablemente la región (Magallanes) se ha

presentado muy apropiada para la cría del

ganado; aunque ofrece como único inconveniente

la manifiesta necesidad de exterminar a los fueguinos" (p. 64) ${ }^{3}$.

En la nota que acompaña la cita, podemos constatar la extensión del viaje por el archivo que propone el autor. Riveros toma esta cita del libro Hombres primitivos en la Tierra del Fuego (de investigador a compañero de tribu) de Martin Gusinde, quien a su vez la recogió de la revista The South American Missionary Magazine XVI, 237, Londres, 1882. La cita en el libro de Riveros, de 1986, nos traslada al libro de Gusinde, de 1951, y de este a la revista de los misioneros ingleses, de 1882 y, por último, a las líneas del periódico publicado en 1872 .

En lo formal, estos fragmentos y sus múltiples fuentes ponen en claro el uso del archivo fueguino en la estructuración del poema y en la transformación de la lectura en un recorrido por el ámbito de los textos aludidos. Estamos ante un doble quiebre: de un lado, el de la recepción pasiva y lineal y, del otro, el de los discursos oficiales, ya que nos acercamos a la particularidad de sus fuentes. Los datos presentes en la nota final traen a la luz las mediaciones que sufren las imágenes de los fueguinos en la mayoría de las publicaciones y, por ende, llaman la atención sobre el andamiaje representacional involucrado en esas proyecciones. En definitiva, la memoria social de estos pueblos y el acercamiento a su cultura, al pasar por este entramado, hacen patente la imposibilidad de una relación auténtica y transparente en el viaje. Para llegar a los pueblos de la "tierra sin fuegos", si eso fuera posible, es requisito pasar primero por los territorios ocupados del archivo, lo cual indica que no existe una otredad en estado natural ni separada de esos discursos.

Otros segmentos de "Exterminio ona (1875-1905)", originados en citas de Martin Gusinde, orientan los significados del viaje por el archivo hacia la denuncia de las atrocidades que cometían los colonos:

En este y otros lugares seguimos el uso de comillas del original. 
Entonces, en virtud de la gran capacidad mercantil de los pioneros: cráneos de indios asesinados “...al Museo de Antropología de Londres, que pagaba hasta ocho libras esterlinas por cabeza. No se respetaban... mujeres... niños... ni ancianos..." (p. 64).

Esta cita, junto a la del periódico inglés, expone los conflictos ideológicos presentes en el archivo cultural y en el mismo libro de Riveros, donde es interpelado el discurso de los colonos. La misma composición, ya desde el título, postula un discurso de denuncia que contradice las relaciones dominantes y que está basado en el respeto por la diferencia, tal cual deducimos de la lectura de Gusinde. En el espacio crítico abierto por Riveros, la configuración poético-documental y la heteroglosia implícita en los conflictos discursivos representan un acercamiento ficcional cuyo trasfondo es el cuidado y la solidaridad con los grupos que habitaban la zona austral. De todas formas, aunque en los poemas hay una posición favorable a esos pueblos, esta es construida a la par de otras voces. Lo dicho de aquellos pueblos no surge de una conciencia totalizadora y autoritaria, sino de la relación conflictiva entre las varias posiciones presentes en los documentos.

Junto a estas características que dirimen los hitos del viaje y subvierten el aparato documental, en "Exterminio ona..." Riveros apunta al nexo inter-temporal entre su presente y las experiencias del pasado. De allí que establece paralelos entre el exterminio de los fueguinos y las tragedias que acosaban el entorno de la escritura, las ocurridas durante la dictadura en Chile. Ejemplo de esta difícil circunstancia es el ataque sufrido por Rodrigo Rojas y Carmen Gloria Quintana, el 2 de julio de 1986, y que Riveros presenta por medio de una cita:

\author{
"Entonces una camioneta militar \\ nos alcanzó. Alguien llenó un envase \\ con bencina y le atornilló un fumigador manual. \\ Un oficial nos roció de rodillas a cabeza. \\ Y tendiéndonos nos arrojaron fuego. \\ Y entonces ardimos" (p. 65).
}

A partir de estas palabras, conviene enfatizar la dirección que cobra el hibridismo en estos enunciados y a lo largo del libro: el hecho de que establece una red de conexiones en torno a estas experiencias del mal que permiten unir las dos temporalidades. A la vista de estos dos planos temporales que unen los avatares de la maldad, el libro expresa el fracaso del pasado histórico en su posible capacidad para modelar el futuro. Por ello, pareciera no haber lecciones positivas en este contacto, excepto el saber que ofrece respecto a la 
reiteración de la violencia y de la tragedia humana. Por sobre la negatividad, las palabras del poeta socavan el silenciamiento de las víctimas y echan luz sobre la recurrencia de la maldad y, por ello, dan pauta a nuevas formas de solidaridad en el rescate ético del pasado y en el testimonio del presente. Así, podemos afirmar que el texto replantea el problema de la dignidad humana y alumbra las continuidades trágicas que determinan el desarrollo de nuestra historia.

"Dawson" es otro poema donde Riveros establece un enlace entre el pasado fueguino y las atrocidades cometidas durante la dictadura. Su propósito es poner al descubierto la continuidad inexorable de la tragedia, a la vez que insistir en la necesaria inmersión crítica en los documentos y en la transformación simbólica de la localidad que fue testigo de esas circunstancias. En cuanto a este último aspecto, la isla Dawson es espacio central de este drama: lugar en la geografía chilena y espacio simbólico marcado por el sufrimiento de los que allí fueron prisioneros. El poema comienza con un epígrafe tomado de Dawson, libro de Aristóteles España, quien fue prisionero político en el campo de detención de isla Dawson, en el territorio austral de Chile. España presenta el testimonio de esa experiencia:

\section{Esa larga fila de Confinados}

que subía a los camiones de la Armada Nacional

marchando

cerca de las doce de la noche del once de septiembre

de mil novecientos setenta y tres en Isla Dawson (Cursivas en el original, p. 67).

Luego de este epígrafe testimonial, los primeros versos ponen de manifiesto las ataduras entre las dos circunstancias al revelar la función carcelaria de Dawson en el pasado: “También campo de concentración/ de onas y alacalufes" (p. 67) ${ }^{4}$. En este poema, afirma Iván Carrasco M. (1998), "Los sufrimientos de los perseguidos y encarcelados onas prefiguran los de sus hermanos chilenos muchos años más tarde en el mismo lugar, superponiendo personajes y situaciones que representan rasgos permanentes o reiterados de la conducta humana" (p. 73). El discurso continúa con una serie de citas que proclaman la necesidad, de acuerdo a los colonos, de trasladar a los fueguinos al campo de isla Dawson:

4 Anne Chapman, una destacada estudiosa de las culturas de la Tierra del Fuego, comenta acerca de la antigua función de isla Dawson: "Entire families were captured and taken by force to the missions, especially to the one on Dawson Island. Some escaped from the latter with the help of the Alakaluf who rowed them back to the shores of their island." "Familias enteras fueron capturadas y llevadas a la fuerza a las misiones, especialmente a la de Isla Dawson. Algunos escaparon con la ayuda de los alacalufes que los llevaron de vuelta a las costas de su isla." Drama and Power in a Hunting Society. The Selk'nam of Tierra del Fuego, 1982, p. 12-13). De aquí en adelante daré mis propias traducciones de las citas en inglés. Las citas largas serán traducidas en notas a pie de página. 
"Con todo, el punto clave es conseguir

una orden por algunos soldados

que nos ayuden a arrinconar a

los indios y llevarlos a Isla Dawson" (p. 69)

Finalmente, Riveros confirma la función de la isla en los dos tiempos: sitio de detención de los fueguinos y campo de concentración bajo la dictadura militar:

Y en 1911, Septiembre,

expiró el contrato de la Misión en Dawson

con un cementerio de ochocientas tumbas (p. 70) .

Dawson quedó a la espera.

"El campo de Compingin, en Punta Grande, fue

'inaugurado' el mismo 11 de Septiembre de 1973

con sesenta detenidos de Punta Arenas....

El último de los 'dawsonianos' recuperó la

libertad en Junio de 1977”' (p. 70).

Un hecho significativo es que esta última cita pertenece a Dawson, el libro testimonial de Sergio Vuscovic, también prisionero en la isla después del golpe de estado. Con esto queremos señalar no solo las coincidencias espacio-temporales en torno a Dawson, sino también el hecho de que esta isla, en el viaje por los documentos citados, empieza a ser transformada en un significante de la represión. Espacio geográfico que deviene símbolo de la tragedia y del terror en los testimonios de España y Vuscovic y es parte de las continuidades que establece la "imaginación ética” desplegada por Riveros?.

Las citas de "Exterminio ona" y "Dawson" desvelan los materiales documentales sobre las cuales han sido elaborados estos y otros poemas; además que demuestran la transformación de la lectura en un viaje por la quebrada geografía del archivo. Se trata de un viaje que incumbe al pasado y al presente y que, agreguemos, va a ser ampliado hacia el campo de las citas literarias. "Exterminio ona”, de hecho, incluye versos de Ezra Pound, Thomas Merton y Saint

5 Una nota confirma que la cita fue tomada de una carta dirigida a Mauricio Braun, fechada el 7 de noviembre de 1896 (Riveros, p. 206).

6 Estos versos de "Dawson" participan del diálogo poético y de la relación intertextual de este poema con Los nómades del mar. Escribe Emperaire: "En septiembre de 1911 expiraba el contrato acordado a la misión de Dawson. La Misión había contado con más de 500 indios en el curso de los últimos años. El cementerio, agrandado varias veces, contaba con 800 tumbas" (p. 76).

7 La idea de una "imaginación ética” la adaptamos del artículo de Jean Franco, “Gender, Death, and Resistance: Facing the Ethical Vacuum" (1999). En ese trabajo, Franco escribe sobre lo que llama "creative acts shaped by moral imagination" ("actos de creatividad moldeados por una imaginación ética”) en el ámbito de la "estetización de la muerte" (p. 19) en el discurso postmoderno. 
John Perse. El mismo conjunto de fotografías, al final del libro, es otro medio de expansión referencial y de la concepción del conjunto poético en la forma de un memorial dedicado a estos pueblos desaparecidos. Por tanto, y basándose en los conflictos ideológicos patentes en estos documentos y poesías, Riveros busca dar legitimidad a una visión alternativa de los varios pueblos de la Tierra del Fuego, a la vez que construye conexiones que recuperan la continuidad de la memoria de esas víctimas en los dramas de su propio tiempo.

Por último, este recorrido revela que las mediaciones discursivas impiden la proyección de un encuentro auténtico entre las diversas culturas. Aún más, la atención dada al seguimiento y cita de los documentos posibilitan el desarrollo de una crítica de las falencias del archivo y del sistema ideológico involucrado en la justificación de la violencia y del exterminio de los fueguinos. La poesía crítica, aquí, conduce a un quiebre de las relaciones deshumanizantes y de la reificación de la historia en los discursos oficiales. Vale reafirmar que el viaje por el archivo y las coincidencias espacio-temporales que ocurren en torno a las experiencias límites de la persona en los poemas, frenan la transformación del retorno al pasado en un acto romántico que supuestamente lleve a los orígenes. Estas coincidencias tampoco permiten que el viaje sea un medio de escape de la realidad de censura y represión que rodea la escritura. El viaje por los documentos y la conexión inter-temporal, en suma, iluminan el pasado y la tragedia fueguina y, al mismo tiempo, testimonian las condiciones que enmarcaban la escritura del libro. En los dos casos, la práctica del mal y, en consecuencia, las grandes pérdidas de vidas humanas a causa de la violencia permitida o planificada por el estado.

\section{LA PEREGRINACIÓN Y EL ENCUENTRO}

Junto a la travesía por el archivo, Riveros poetiza el encuentro al transformar el viaje en peregrinación; no un viaje unidireccional por territorios reales sino una ficción del viaje en la cual hay un recorrido por una geografía imaginaria, aunque enmarcada por ciertos hitos reconocibles, los de la Tierra del Fuego. Una cita de Thomas Merton, que da inicio a la sección titulada "Precauciones", resume las posibilidades que abre la peregrinación en esta modalidad del acercamiento en el libro:

“... es una peregrinación, no es un viaje sentimental a un pasado romántico, sino un esfuerzo humilde, difícil $y$ necesariamente incompleto por cruzar un abismo y llegar a una comunión con gentes a quienes, privadas en tan gran medida de su identidad y reducidas al silencio, queda poco o nada que decir en el lenguaje ordinario" (Comillas y cursivas en el original, p. 27).

A primera vista, en lo formal, este epígrafe encarna otra manifestación del "collage" 
(Carrasco, 1998, p. 80) intertextual que sustenta la estructura de los poemas y que ya vimos en la hibridez de "Dawson" y de "Exterminio ona". De fondo, la cita cumple una función estructurante y meta-poética pues, además, resume un conjunto de ideas que serán ampliadas en torno al acercamiento, principalmente las de peregrinación y comunión, pasando por las de identidad, silencio y lenguaje.

Thomas Merton, en “The Shoshoneans”, un artículo incluido en Ishi Means Man (1976) y del cual sale el epígrafe citado, afirma que la peregrinación ("pilgrimage") es "[a] journey to the source, a return to a place where there will be an encounter and a renewal of life." ("[un] viaje a los orígenes, un retorno a un lugar donde habrá un encuentro y una renovación de la vida.” p. 7). Pero el mismo Merton, ya claro en el epígrafe y en el artículo, una reseña del libro The Shoshoneans de Edward Dorn y Leroy Lucas, señala que ese encuentro y el conocimiento de aquellos "privados de identidad y palabra" que intentan los autores de The Shoshoneans no se logra y que, por tanto, el retorno forjado en la peregrinación no es más que la expresión de un deseo de unidad en esta práctica del viaje. No es, en otras palabras, un retorno idealizado al origen:

The book is quietly eloquent, objective, without camouflage, confessedly incomplete and tentative. It is an attempted pilgrimage to the point "beyond which there would lie the fullest explanation of a people who have been so fully maligned by crimes of omission." The authors have the honesty to admit that they never reached any such a point (p. 8) . $^{8}$

De manera similar, en Riveros constatamos un intento de acercarmiento a los espacios de la otredad y de proyectar el acercamiento, aunque el poeta no pretende edificar una explicación completa de lo indígena a partir del viaje ni en base al saber legitimado por el archivo. Contradiciendo el discurso dominante, la peregrinación que propone Riveros, a partir de Merton, implica un encauce alternativo del acercamiento, uno opuesto al viaje de conquista y de control de las culturas locales. Por esta razón, en la peregrinación hallamos una actitud de constricción y de solidaridad que tiende a la comunión, explícita en el citado epígrafe de Merton y desarrollada en el conjunto poético.

Peregrinación y solidaridad son dos conceptos que ya otros críticos han identificado en este conjunto. Entre ellos, Iván Carrasco M. plantea que para el sujeto del viaje la “peregrinación ha sido una verdadera experiencia de vidente o poseso" (p. 75)9. En el mismo

8 "El libro es humildemente elocuente, objetivo, sin camuflage, abiertamente incompleto y tentativo. Es un intento de peregrinación a un lugar 'en cuyo más allá se encontraría la explicación completa de un pueblo que ha sido perjudicado por crímenes de omisión.’ Los autores tienen la honestidad de reconocer que nunca alcanzaron ese lugar" (p. 8).

9 Asimismo, los editores de la antología Las plumas del colibrí (1989) comentan la función de la peregrinación y de la comunión en el libro de Riveros:

La lectura en palimpsesto muestra que este peregrinaje es doble cruce de abismo, porque se llega a la comunión con los desaparecidos del pasado y a la vez con los desaparecidos del presente. Doble cruce que en realidad es uno solo si se considera de qué murieron los hombres de las dos tragedias cuyo responso poético es De la tierra sin fuegos (p. 82). 
artículo, Carrasco además comenta y precisa la noción de solidaridad que encontramos en el libro:

De la tierra sin fuegos es un texto complejo y plural, conformado por un conjunto discursivo de naturaleza heterogénea, pero unificado por un sentimiento de solidaridad hacia los indígenas del sur austral, solidaridad de motivación religiosa cristiana en concordancia con la poética de Riveros (p. 70).

Siguiendo estas palabras, podemos recalcar lo que este crítico llama la "motivación religiosa cristiana" presente en este acercamiento al otro y, por ende, en la peregrinación. Se trata de una poética tensionada por las creencias cristianas y las propias de los fueguinos; por este motivo, la religiosidad proyectada a través de la peregrinación constituye un híbrido cultural sostenido precariamente en los límites de varios sistemas de creencias. De nuevo, la diferencia fundamental entre este pensamiento y la tradición colonial es que estos enunciados poéticos intentan un acercamiento a las creencias fueguinas y no se impones sobre ellas con un saber totalizador que excluye o subordina el mundo espiritual de aquellos pueblos.

Ahora bien, las cuestiones relacionadas con la espiritualidad y el impulso místico del libro, siguiendo el comentario de Iván Carrasco M., abren la peregrinación hacia un importante campo de significados que tienen que ver con sus posibles fuentes teológicas. De la misma manera, la concepción de la peregrinación en cuanto práctica o praxis del acercamiento a la otredad sin duda atañe a estos fundamentos. Praxis es un término desarrollado por Enrique Dussel en Ethics and Community, uno de sus trabajos sobre la teología de la liberación. Dussel escribe: “Praxis' or 'practice' means many things in our daily life. For my purposes in this work I take these terms in their strict sense: praxis or practice denotes any human act addressed to another human person; further, praxis denotes the very relationship of one person to another. Praxis is both act and relationship..." ("La 'praxis' o 'práctica' significa muchas cosas en nuestra vida diaria. Para mis propósitos en este trabajo, uso estos conceptos en su sentido estricto: praxis o práctica denotan cualquier tipo de actividad humana dirigida a otra persona; aún más, la praxis expresa la esencia de la relación entre las personas. La praxis es, al mismo tiempo, acción y relación” p. 8). A continuación, Dussel clarifica el carácter ético de la praxis en su filosofía: "Praxis, then, is the actualization of proximity, of the experience of being proximate, for one's neighbor. Praxis is the experience of constructing the other as person, as end of my action and not as means. We are dealing with a relationship of infinite respect" ("La praxis, entonces, es la actualización de la proximidad, de la experiencia de la cercanía ante nuestros vecinos. La praxis es la experiencia de imaginar al otro como persona, como fin de mis acciones y no como un medio. Estamos hablando de una relación de infinito respeto" p. 9-10, nuestro énfasis).

Ayudándonos de esta conceptualización consideramos que la praxis o la acción en sí, connota el esfuerzo de la peregrinación y el cruce de instancias liminales que transforman 
positivamente el carácter del contacto. En tanto vínculo, la praxis sustenta la posible creación de un sentido de comunidad, de una relación cara a cara con la otredad. A partir de la definición de Dussel, pensamos que la praxis desplegada en la peregrinación, la praxis de fondo místico, es una acción de alto valor ético, pues, tal cual es desplegada en el libro, participa de las creencias fueguinas y tiene una profunda actitud de solidaridad con las víctimas. Paralelo al viaje por el archivo, donde el hibridismo discursivo permite develar el entablado sobre el cual han sido construidas las imágenes del otro (donde generalmente se lo ha deshumanizado), la peregrinación o praxis místico-solidaria en la ficción de Riveros, es un intento por hacer presente la proximidad con el otro en un ambiente de respeto por la diferencia y la integridad de la persona.

La peregrinación y comunión en las reflexiones de Merton y la noción de praxis o de acción y vínculo (comunidad) de Dussel, las podemos enlazar con el estudio de la peregrinación desarrollado por Victor Turner en Dramas, Fields and Metaphors. Simbolic Action in Human Society (1974). Notemos que el trabajo de Turner, a diferencia de la perspectiva teológica de los autores anteriores, profundiza en el significado etnológico, científico, de la comunidad y de la liminalidad. En la obra de Turner, la peregrinación está imbricada con la "communitas", una estructura alternativa a las formas reguladas y organizadas de sociedad, según el etnólogo. Puesto que está basada en lazos sociales igualitarios, la peregrinación tiende a crear una estructura social-otra, fundada en lo que Turner llama "a community of feeling” ("una comunidad de sentimientos" p. 201). Para el mismo autor, "the bonds of communitas are anti-structural in that they are nondifferentiated, equalitarian, direct, nonrational (though not irrational)..." ("los lazos de la 'communitas' son anti-estructurales en tanto son indiferenciados, igualitarios, directos, no-racionales (aunque no irracionales)...” p. 46-47). Así es que, en una perspectiva general, similar a la que elabora Riveros, la peregrinación crea nuevos lazos comunitarios para la práctica del acercamiento y de la representación de la otredad.

De las palabras de Turner deducimos que la peregrinación es un fenómeno social al margen de las formas reguladas de la vida cotidiana. Atañe más bien a una instancia de quiebre del orden tradicional, reemplazado por otras normas estructuradas alrededor de categorías de comunidad que surgen, por ejemplo, del imperativo por concretar un encuentro místico y liberador. Para Turner, esta marginalidad social y la índole fronteriza de las experiencias del viajero le dan un carácter "liminal” a la peregrinación. La peregrinación, efectivamente, supone cruzar una serie de instancias liminales, lo que Turner llama “a limen... a 'threshold'” ("un umbral... un 'límite”" p. 197), las cuales involucran estados cercanos a los ritos de iniciación y que en el peregrinaje tienen sentidos expiatorios y terapéuticos. A continuación, veremos que, en la peregrinación poética, esta liminalidad es visible en los fundamentos precarios que sustentan el viaje y en el dramatismo de las experiencias del peregrino.

En base a estas formulaciones relacionadas con la peregrinación, hay que notar que en De la tierra sin fuegos es de vital importancia el cumplimiento de una prueba de paso 
o el cruce de un "limen" antes de ingresar en la comunidad local. Al inicio del poemario, la articulación poética del viaje comienza con unos versos que dan cuenta de la captura de un viajero anónimo y de su entrada en el espacio indígena:

...Un poco más allá de los Cantiles del Sur, de los que fluían insignificantes riachuelos, fui detenido silenciosamente.

Mis captores, de fisonomías extremadamente imprecisas y cuyas voces no recuerdo en nada, me condujeron como a tientas (p. 9).

Naturalmente, el "limen" ocurre en el momento de la detención del hablante, un hecho ambiguo que trastorna los supuestos básicos del archivo, donde el extranjero por lo común ha sido presentado en posición de poder. En contraste, la situación subordinada del peregrino neutraliza la posibilidad de control y niega la acostumbrada violencia que enmarca esos eventos. Notemos que esta subordinación y la condición marginal del sujeto son otros de los factores centrales en la creación de comunidad o "communitas". Al respecto, afirma Victor Turner:

Communitas breaks in through the interstices of structure, in liminality; at the edges of structure, in marginality; and from beneath structure, in inferiority. It is almost everywhere held to be sacred or "holy," possibly because it transgresses or dissolves the norms that govern structured and institutionalized relationships and is accompanied by experiences of unprecedented potency (The Ritual Process, 1969, p. 128) ${ }^{10}$.

Por lo tanto, la captura y subordinación del personaje suponen el cruce ritual de una frontera donde es despojado de sus atributos de poder; este rite de passage lo "humilla" y prepara para la entrada en la comunidad y para la futura unión en la sociedad indígena.

Cabe notar que, junto a esta condición subordinada del peregrino, el encuentro ocurre en una zona imprecisa y liminal, los "Cantiles del Sur". Dicha ignorancia de la geografía es contraria al afán por definir o nombrar el lugar, notable entre los viajeros europeos que buscaban apropiar o neutralizar la extrañeza de lo desconocido en sus viajes de exploración y conquista. La visión del espacio indígena que ofrece el peregrino es casi irrelevante por lo común, aunque está cargada de un cierto misterio: "Penetramos en un pueblo pequeño, sin ninguna importancia si lo comparamos con las ciudades del mundo, que, como un convento

10 “'Communitas' surge de los intersticios de la estructura, en la liminalidad; en los bordes de la estructura, en la marginalidad; y desde debajo de la estructura, en la inferioridad. En casi todos los lugares se la considera sagrada o "santa," posiblemente porque quiebra o elimina las normas que gobiernan las relaciones estructuradas e institucionalizadas y es acompañada por experiencias de alta intensidad”. 
primitivo, yacía hundido en un silencio conmovedor...” (Riveros, 1989, p. 9). El espacio indígena es un territorio de contornos ambiguos, que contrasta con la geografía de la colonización y que prepara al viajante, en esta condición del ser a la intemperie, para la creación de los lazos de unidad material y espiritual desarrollados más tarde. Asimismo, la comparación de la localidad con "un convento primitivo" y el "silencio conmovedor" que lo envuelve caracterizan el espacio con cualidades místicas relacionadas con la adaptación poética de la peregrinación. Habría que subrayar, en todo caso, que la ambigüedad de este espacio atenúa su posible sacralización; este es un sitio ordinario, aunque misterioso por lo desconocido.

La vaguedad que rodea la presencia de los partícipes es otro dato que contribuye a la ambigüedad de la acción. El peregrino, que ha sido detenido, no llega a asignar significados inmediatos a su experiencia ni a la figura de los captores. No transforma la primera impresión en un saber totalizante de lo indígena. Habla "de fisonomías extremadamente imprecisas" y su vista de los captores es ambigua: "Sabía de sus presencias por una opresión indefinida y por rastros que, en su tiempo, nada significaron” (p. 9). Paralelas a estas indefiniciones hay que sumar las menciones a la voz y al idioma desconocido, dos aspectos que incrementan la indeterminación del momento. Las únicas palabras que lo median son de los indígenas que comandan la acción y le ordenan en lengua ona: “Were, wenne wint” (“¡Pronto ven acá!,” p. 10; la traducción es de Riveros y aparece al pie de la misma página). Luego impera el silencio, el individuo no recuerda las voces o no las distingue, el silencio tiene un tono acusatorio y el idioma es incomprensible: "La comunidad extranjera, por su lengua desconocida, por su comportamiento peculiar y por aquel silencio que constituía una especie de acusación gratuita, parecía desprovista de todo vestigio occidental” (p. 9). Vale reiterar que la captura y estas ambigüedades de las voces en la liminalidad del encuentro expanden el propósito crítico de estos enunciados, es decir, el rechazo de las relaciones tradicionales del contacto y de sus representaciones de lo indígena.

En contraste con este conocimiento parcial del peregrino o con la integración cuidadosa en Gusinde, podríamos recordar otro episodio memorable que ha cooperado en el silenciamiento de los fueguinos y en la falsificación de su identidad. Me refiero al narrado por Charles Darwin en su Beagle Diary (1988). Esta es la descripción que hace del incidente y de los Selk'nam:

It was without exception the most curious \& interesting spectacle I ever beheld. -I would not have believed how entire the difference between savage \& civilized man is. -It is greater than between a wild \& domesticated animal, in as much as in man there is greater power of improvement.... From their dress \&c \&c they resembled the representations of Devils on the Stage, for instance in Der Freischutz (Entrada para el día 18 de diciembre de 1832; p.122)11.

11 "Fue, sin duda, el espectáculo más extraño e interesante que nunca había visto. - No habría podido creer cuan completa es la diferencia entre un salvaje y un hombre civilizado. - Es más grande que entre un animal salvaje y uno domesticado, en la medida en que en el ser humano hay más capacidad para progresar.... A partir de sus vestimentas... ellos semejan representaciones de los Diablos en el escenario, por ejemplo, en Der Freischutz". 
Darwin intenta explicar la alteridad a través de representaciones que subordinan la cultura local a un código europeo que le es familiar, el teatro, y a través de este medio, controla simbólicamente la imagen del otro y lo distancia al transformarlo en una entidad demoniaca ${ }^{12}$. Darwin hace de la visión del indígena un espectáculo donde no hay espacio para el vínculo; lo que observamos, más bien, es el incremento de la distancia en la negativa ideologización de lo autóctono o local ${ }^{13}$.

Sin embargo, la ambigüedad del hallazgo y las limitaciones del conocimiento del peregrino no suponen olvidar al fueguino, aunque a diferencia de los documentos del archivo este retrato solo aparece después de un recorrido por el espacio físico e intelectual de estos pueblos. El poema "Selknam", que recoge las huellas del discurso contestatario y testimonial de Gusinde, nos presenta con una de esas imágenes:

\author{
Altos, magníficamente proporcionados. \\ Cara ancha, ovalada, pómulos salientes, \\ ojo negro como el cabello. \\ "Boca ancha, ordinariamente abierta \\ a la maravilla o la sonrisa." \\ ... \\ Perfecta posición, vertical \\ tranquilidad y dominio de sí. \\ El carácter moral: "semejante al de otro hombre \\ cualquiera” (p. 77) ${ }^{14}$.
}

En oposición a las historias ya acostumbradas, la actitud de este viajero es la de conocer lo sustantivo de la cultura aborigen y luego intentar la proyección de su figura. Aún más, en este poema, y en el libro, la peregrinación y la creación de la comunidad, en la "construcción del 'otro'

12 Michael Taussig en Mimesis and Alterity. The Particular History of the Senses (1993) estudia esta teatralidad en la descripción de Darwin y las complicaciones que presenta la mimesis en el contacto.

13 Anne Chapman informa que ya desde los primeros viajes había dominado la violencia de los europeos hacia los pueblos fueguinos:

The Selk'nam first encountered Europeans in 1579 in the person of the Spaniard Pedro Sarmiento de Gamboa and some of his men. The meeting occurred on the west coast of the island at a place which Sarmiento named Bahía de Gente Grande ... in honour of the Selk'nam. Despite the peaceful reception they were accorded, the Spaniards proceeded to kidnap one of the Sel'knam. The volley of arrows which ensued wounded a Spaniard but the Selk'nam was still abducted (p. 9).

“El primer encuentro de los Selk'nam con los europeos fue en 1579, con el español Pedro Sarmiento de Gamboa y algunos de sus hombres. El encuentro ocurrió en la costa oeste de la isla en un lugar que Sarmiento llamó Bahía de Gente Grande... en honor a los Selk’nam. A pesar de la pacífica recepción que se les dio, los españoles secuestraron a uno de los Sel'knam. La lluvia de flechas que descargaron hirió a un español, pero el Sel'knam fue igualmente capturado".

14 Este poema hace evidente el diálogo intertextual que realiza Riveros con la obra de Gusinde. El texto surge de la poetización del siguiente fragmento: “Hombres altos y magníficamente proporcionados son nuestros Selk'nam.... La perfecta posición vertical, la tranquilidad del dominio de sí mismo, la penetrante mirada, la fisonomía facial perfectamente acusada..." (p. 48). 
como persona” (Dussel, p. 8), están sustentadas en la documentación de Gusinde, quien vivió entre los fueguinos a principio de los años veinte. Gusinde, al contrario de las representaciones que aparecen en Darwin, ofrece una visión que respeta la diferencia y no deshumaniza al otro.

En relación a la presencia de la otredad, notemos que es en el mismo libro de Gusinde, Hombres primitivos en la Tierra del Fuego (de investigador a compañero de tribu), donde aparecen la mayoría de las fotografías de los fueguinos reproducidas por Riveros, incluida la del rumano Julius Popper "en una cacería de onas” (Riveros, p. 192-193). Estos documentos fotográficos son otros de los medios que Riveros usa para reconstruir el encuentro y subvertir la negatividad de las imágenes dominantes. La fotografía establece un punto de quiebre con el código verbal y con la noción tradicional del libro de poemas al transformarlo en documento de la existencia material del otro. Iván Carrasco comenta que "Los documentos fotográficos conforman un lenguaje particularmente conmovedor, porque le otorgan corporalidad a los hombres y mujeres mentados en los textos" (p. 74). Estas imágenes subrayan la tragedia de la desaparición de las culturas sureñas y de otras desapariciones durante el periodo dictatorial.

Un contraste similar al apuntado en cuanto a las imágenes corporales ocurre en relación al idioma de uno de los pueblos del sur. En Riveros, tal cual notamos en "Precauciones", las voces de los indígenas son ambiguas y el idioma, desconocido. A Darwin, en su memorable primer encuentro, el lenguaje de sus interlocutores lo lleva a un comentario despectivo:

Their language does not deserve to be called articulated: Capt. Cook says it is like a man clearing his throat.... Imagine these sounds \& a few gutturals mingled with them, \& there will be as near an approximation to their language as any European may expect to obtain. (p. 124) ${ }^{15}$.

En "Yámanas II", Riveros rescata el valor de este idioma tan despreciado por los colonos: "Treinta y dos mil suavidades, su lengua/ Riqueza, no en los bancos, sino/ en el verbo" (p. 94). Es de interés notar que, Armando Braun Menéndez, un colonizador que participaba en la explotación de los indígenas, siente admiración por el idioma de los Yámana: "el idioma que poseían era increíblemente rico en voces, giros y expresiones” (p. 38). Bruce Chatwin en su libro de viajes, In Patagonia (1977), cita algunos usos que reflejan la riqueza metafórica del idioma de este pueblo austral:

What shall we think of a people who defined 'monotony' as 'an absence of male friends?' Or, for 'depression,' used the word that describes the vulnerable phase in a crab's seasonal cycle, when it has sloughed off its old shell and waits for another to grow? (p. 136) ${ }^{16}$.

15 “Su lenguaje no merece la calificación de articulado. El Capitán Cook dice que es como un hombre carraspeando... Imaginen esos sonidos y unas cuantas guturales mezcladas con ellos, y tendrán una aproximación a su idioma tan similar como a la de cualquier otro europeo".

16 “¿Qué se podría pensar de un pueblo que define la 'monotonía' como 'una ausencia de amigos hombres?' O, que para la 'depresión,' usaban la palabra que describía la etapa vulnerable de los cangrejos durante su ciclo estacional, cuando se les ha desprendido su vieja caparazón y esperan a que crezca otra." Chatwin cita otros sinónimos interesantes: "Sleet - fish scales... A tangle of trees that have fallen blocking the path forward - A hiccough... Mussels out of season -Shrivelled skin - Old age” (p. 136). "Nieve aguada - escamas... una maraña de árboles que han caído y bloqueado el camino - el hipo... mejillones fuera de estación - piel arrugada - vejez”. 
De esta manera, la búsqueda de un nuevo espíritu de comunidad en la peregrinación poética o en la ficción del contacto pasa por la experiencia liminal de la detención, por la representación ética de las imágenes del otro y por el rescate de la riqueza del idioma local. Junto a estos elementos contrastantes y subversivos de las relaciones tradicionales del encuentro, Riveros suma su propia versión creativa de las voces fueguinas, dando inicio a una recuperación del habla de esos pueblos desaparecidos. En este caso, vuelve a haber un contraste de esta obra con el archivo. No escuchamos las voces de la otredad en esas relaciones; siempre hay un sujeto externo que la define o que habla por ella. Riveros, entretanto, despliega un gran número de voces que van desde aquellas testimoniales de los fueguinos, pasando por las de quienes los deshumanizan, hasta llegar a las de denuncia de Gusinde y Emperaire. Ya hemos señalado que el libro está construido en torno a esta multiplicidad de voces, de hablas yuxtapuestas y enfrentadas que desmitifican lo oficial. "Despedida" contiene una muestra del habla indígena:

Estoy alegre. No tenemos motivo para separar-

nos de esta tierra con tristeza: No es ona

la tristeza.

Llegará el día en que muera el penúltimo

Selknam. Y nadie pronuncie nuestra

lengua o sepa de Quenós, de Cuanyip o Taiyin. Y ya nadie

hable con Temáuquel.

Sépanlo: me he atenido a la más

estricta verdad (p. 81).

Este y otros poemas demuestran que, a diferencia de las formas dominantes del archivo, donde el habitante local ha sido comúnmente silenciado, este discurso imagina un rescate de la presencia del otro, a la vez que intenta recuperar la voz de las víctimas en el marco de la ficción poética. Esta creación es, por tanto, un acto de cuidado: Riveros no asume un papel totalizante cargado de negatividad ni tampoco idealiza esas presencias; lo que esas voces nos comunican es el tránsito de una cultura por un momento crucial. Tal cual comenta Mauricio Ostria, "Aquí no hay arcadias futuras ni paraísos recuperados, sólo un triste silencio, una dolorosa comprobación, una queja y, quizá, sólo quizá... una lección de la suprema dignidad de un pueblo en la hora de su muerte" (p. 172). En este espacio liminal, que es el de la desaparición y del reencuentro poético con la otredad, no hay razón para la nostalgia; el reclamo que nos hace el discurso es el de la verdad. Práctica problemática por el silenciamiento que rodeó el exterminio de los Selk'nam, Yámana y Kawésqar, y por las censuras que se vivían durante los años ochenta. 
Para resumir, en el libro los varios estados de la peregrinación y el sufrimiento de experiencias liminales hacen de la praxis un vínculo creativo. Riveros, en otras palabras, va delineando una posibilidad poética para la concreción de un encuentro que recuerda la literatura de contacto, pero que se aparta de ella. Esta ética de la peregrinación, cuestión que pasamos a elaborar en el siguiente y último apartado, alcanza finalmente a la realización del vínculo en la comunión.

\section{LA COMUNIÓN}

En De la tierra sin fuegos, la peregrinación, la aproximación misteriosa hacia la comunidad indígena y la posibilidad de testimoniar el habla de los fueguinos tiende a la creación de lo que, en otro lugar, Victor Turner llama "the communitas", una praxis del vínculo que nace en la relación de persona a persona (Dussel). Esta comunidad implícita en la acción del viaje y en el hallazgo imaginado del habitante nativo en Riveros, rompe con los estatutos sociales dominantes y crea un nuevo orden que vemos emerger en el rescate de discursos alternativos que enjuician las imágenes devaluativas de los fueguinos. El estado culminante de esta “communitas” es el de la comunión, instancia materializada en varios niveles de la ficción poética, entre los que destacan: el encuentro respetuoso entre culturas, la aceptación de las diferencias, el rescate de las memorias y la celebración de la continuidad de la vida aun en el contexto negativo de las tragedias y traumas que marcan la relación entre pasado y presente. Junto con esto, la praxis de la comunión alcanza su realización más dramática en dos estados cruciales, me refiero a la "espiritualización-caspi" del viajero y a su integración en la vida local. En lo que sigue estudiaremos estos dos aspectos de la comunión.

En cuanto al primer estado, algunos de los poemas despliegan la transformación del ser histórico, Martin Gusinde, en ente principal del viaje poético y, en un punto más elevado de su integración, imaginan la transmutación de su figura en espíritu. Este hecho es consecuente con el impulso místico de la peregrinación y se completa, en una forma de comunión intercultural, en la unión de las nociones de espíritu y "caspi”: “Oh, espíritu bueno, el caspi de Gusinde, / hermoso, / como el cuello negro del cisne / que fulge...” (“Caspi”, p. 41). Los primeros versos revelan algunos de los indicios de lo espiritual en esta palabra:

Compleja abstracción ona: En la sombra

de un hombre; en el reflejo de un rostro en lo íntimo del agua; en un indicio luminoso

de la selva o en la débil capa de humo.

¡Prevención del infortunio, el caspi! (p. 41).

En el glosario, al final del libro, Riveros da la siguiente definición de caspi: 
O Kaspi, palabra selknam. Es el ánima o espíritu como una sombra impalpable. "El reflejo del rostro en una fuente cristalina" que al tratar de asirse huye o se desfigura hasta el desaparecimiento. También es aquello que permanece de un muerto, lo que queda luego de su desaparición terrenal. También usaban para designarla, la palabra man (p. 198).

Caspi-espíritu es el vínculo que une, en Gusinde, el pensamiento místico de los pueblos indígenas con una expresión que viene de la cultura del etnólogo. Estamos ante la transformación de la identidad del personaje en un híbrido que representa la búsqueda y la concreción simbólica del encuentro intercultural en el libro.

Habría que aclarar, a partir del glosario, que no es posible cerrar la palabra "caspi" con una definición; incluso las nociones de ánima y espíritu parecen ser insuficientes para emular la riqueza ambigua de la palabra. Ni "caspi" ni "espíritu" son abstracciones fijas, más bien representan un conocimiento que al parecer llegamos a obtener, pero que se torna ambiguo cuando intentamos controlarlo: caspi "es el ánima o espíritu como una sombra impalpable”, escribe Riveros ${ }^{17}$. La relación caspi-espíritu confiere un nuevo valor a las nociones de comunidad y comunión en el espacio del intercambio cultural. Este valor queda expresado en el hecho de que la mencionada imagen subvierte la reificación de la comunidad y nos ayuda a entender la comunión no en la fórmula de la subordinación de uno por el otro sino de un intercambio material y simbólico entre dos culturas. La peregrinación hacia la otredad y la unión de espíritu y caspi en la persona poética de Gusinde dan forma a un umbral cultural o "limen" que, al mismo tiempo que nos allega al mundo indígena, nos impide su apropiación. La tragedia de este gesto apuntado por Riveros es que ocurre en el borde del desaparecimiento, transformando la celebración en duelo.

En este terreno ambivalente de la identidad híbrida del viajero y de la transformación de la celebración en duelo entendemos que la comunión no es un acto que completa y delimita el encuentro; es justamente esta relación, en la unión caspi-espíritu, la que abre el intercambio cultural hacia nuevas posibilidades. Ubicada en la frontera liminal de este enlace, la comunión es simbólica de la ética del viaje, de una praxis consciente de las limitaciones impuestas sobre el contacto, sea por la distancia cultural o porque el acercamiento a esos grupos desaparecidos exista solo en las mediaciones del archivo.

Otro aspecto de la creación de comunidad, de la comunión y de la proyección del vínculo a través de la espiritualización-caspi, es el que ocurre en la relación cara a cara. Esta unión es consumada por medio de la transformación de Gusinde en miembro de la tribu:

17 En este punto quisiéramos destacar otro rasgo de la lectura crítica de la palabra "caspi”. Me refiero a la transformación del mismo libro en un "texto caspi”, un escrito abierto, siempre en pos de una forma creativa de comunión con la otredad. Aquí seguimos el acertado comentario de Juan Gabriel Araya (1987) cuando escribe: "Si tuviésemos que definir la obra de Riveros diríamos que es un texto "caspi”, un texto absolutamente fiel a la imagen que convoca y la que se mantiene de un pueblo muerto" ("Escritos de la Patagonia"). 
Conocí el nombre de las aves, plantas, bahías, islas y animales. Y en noches frías y lluviosas me cubrí con sus cantos lastimeros; compartí la alegría de una abundante pesca. Supe los secretos del Chiesjaus.

$\mathrm{Y}$, comiendo choros, me incorporé a la tribu (“Yámanas IV”, p. 105).

Una de las características centrales de este poema es que, junto a las imágenes de la integración, hay, además, un breve desarrollo de otras que materializan el ritual de la comunión cristiana: “...comiendo choros, / me incorporé a la tribu”. Ligado a la doble identidad de Gusinde, este rito de la comida compartida entraña la postulación de otro híbrido cultural puesto que aquello que simboliza la comunión e integración proviene del mundo indígena: "comiendo choros". Consignemos que esta no es tanto una desacralización del ritual sino su transformación debido a las condiciones culturales y materiales que rodean el acto. El último verso, "me incorporé a la tribu," es otra manifestación del referido ritual, aunque en un plano más abstracto, ya que el "incorporé" contiene la fuerza del traer hacia sí mismo, en el prefijo "in”, o hacia el cuerpo, connotado por la raíz latina: corpus, corporis. En la peregrinación, la integración del sujeto, por mediación de la comida, instituye un nuevo estado liminal: momento crucial que, no obstante, se nutre de lo cotidiano y que no supone la imposición de un saber trascendente al culminar el encuentro ${ }^{18}$.

Por consiguiente, la integración resultante de la peregrinación y de la comunión es satisfactoria pues no está aislada de la vida, del idioma ni de las creencias fueguinas. Este hecho la diferencia de la actitud de los colonos y misioneros que transformaban el mero contacto superficial en un saber totalizador del supuesto barbarismo de esos pueblos. Tal cual hemos referido en las citas anteriores, la comunión supone el cruce de ciertas barreras que hacen de la peregrinación o del viaje una experiencia límite que abre la posibilidad de la comunidad con los otros; pero, no obstante, esta profundización de la relación cara a cara, es notable que esto no significa el cierre del acercamiento.

18 Ante esta ética del contacto, vale recalcar que el mismo Gusinde, en Hombres primitivos..., ya había reflexionado sobre la importancia de atemperar la distancia cultural en la participación del investigador en la vida cotidiana del "otro" en todos sus niveles. Escribe el etnólogo:

Más por mis observadores que por mí mismo me había dado cuenta de cómo me había acostumbrado a la vida y quehacer indio; todos los días y durante muchas horas, me sentaba en sus cabañas cupuliformes o acompañaba a los hombres en sus rápidos recados; procuraba comprender sus trabajos y me hacía enseñar dócilmente todo cuanto traían entre manos. Solícitamente me ayudaron en el aprendizaje de su lengua y se alegraron de mis progresos (p. 139).

La integración y comunión de Gusinde es más completa puesto que fue invitado a participar en una de las últimas ceremonias de los Onas, el "hain”, un rito secreto de iniciación. 
En efecto, del libro de Riveros deducimos que el encuentro final con los fueguinos o el retorno a los orígenes en el viaje poético es imposible porque el mismo discurso va negando esas posibilidades en las contradicciones del archivo y en las ambigüedades que socavan las posibles bases totalizantes de la peregrinación y de la comunión poética. En este marco, hemos señalado el enfoque dominante implícito en la documentación, que tiende a una visión negativa de las culturas de la Tierra del Fuego y privilegia la supuesta superioridad del sujeto foráneo. La liminalidad de la peregrinación es otro factor que subvierte la teleología del viaje y la resolución del proceso en un final totalizador en la comunión. Esto ocurre debido a que la trascendencia de la unión espiritual y material es tensionada, en el primer caso, por las ambigüedades que presenta el concepto de "caspi" y, en el segundo, porque el ritual de la comida compartida es un híbrido que atempera la elevación de aquel momento de unidad. Del mismo modo, la transformación de Gusinde en miembro de la tribu no es transparente pues está marcada por una dialéctica de persistencia y transitoriedad: persistencia porque la integración era culturalmente relevante para Gusinde y para los Selk'nam puesto que el trabajo del etnólogo les daba una posibilidad de permanencia ante la destrucción de su cultura; transitoriedad por lo precario de la situación de los fueguinos y porque Gusinde debe dejarlos:

Y entonces partí definitivamente.

Me separé de aquellos espléndidos hombres, como recién salidos de la mano de Temáuquel.

Me alejé de la ternura de sus mujeres, de sus formas de vivir. Acaricié, por última vez, a los niños que me miraron con sus caras tristes.

Mankatschen, el Hombre Captador de Imágenes, se va, dijo el pueblo (“Despedida de Martín Gusinde 1923”, p. 155).

En consecuencia, el peregrinaje y la comunión tienden a desmitificar y negar la postura central del discurso de los viajeros que promovía una imagen deshumanizante del indígena. El encuentro tampoco es un acto romántico, de retorno a los orígenes o a un punto idealizado en el pasado donde el peregrino llega armado de una visión preconcebida o donde la otredad existe en un estado adánico. Lo que Riveros nos presenta es una geografía cargada de accidentes textuales, de conflictos ideológicos y discursivos que minan los fundamentos que sostienen las imágenes devaluadoras de los pueblos australes.

De este modo, en sus poemas, Riveros enfrenta el discurso criminal de los colonos y les opone las voces de Gusinde y Emperaire. Al mismo tiempo, esta exploración de la violencia del pasado y del exterminio de los fueguinos es expandida al reconocimiento de la represión que se vivía en Chile bajo la dictadura militar. Se trata de una continuidad de la violencia que 
parece decirnos que no hay redención para las víctimas, excepto cuando el acercamiento está determinado por un gesto solidario. En la poesía de Riveros, la solidaridad está latente en el viaje poético y es la cualidad que asume el cuidado por el otro en el contacto y en la comunión con las memorias de los pueblos desaparecidos. Es por estas cualidades que se podría decir que De la tierra sin fuegos es una obra que intenta recobrar la dignidad de aquellos pueblos expoliados y exterminados por la violencia, el olvido y la injusticia.

\section{REFERENCIAS}

Araya, J. (1987). Escritos de la Patagonia. La Discusión. Chillán, Chile, 5 de marzo de 1987. Sin número de páginas.

Braun, A. (1946). Pequeña historia fueguina (2da ed.). Buenos Aires: Emecé Editores.

Carrasco, I. (1998). De la tierra sin fuegos: voz de los que no tiene voz. Revista Chilena de Literatura, 52, 69-82.

Chapman, A. (1982). Drama and Power in a Hunting Society. The Selk'nam of Tierra del Fuego. Cambridge: Cambridge UP.

Chatwin, B. (1977). In Patagonia. Great Britain: Jonathan Cape.

Darwin, C. (1988). Charles Darwin's Beagle Diary. Ed. Richard Darwin Keynes. Cambridge: Cambridge UP.

Dussel, E. (1988). Ethics and Community. Trans. Robert R. Barr. Maryknoll, New York: Orbis Books.

Emperaire, J. (1963). Los nómades del mar. Trans. Luis Oyarzún. Santiago de Chile: Ediciones de la Universidad de Chile.

Franco, J. (1999). "Gender, Death, and Resistance: Facing the Ethical Vacuum". Critical passions. Selected Essays (p. 18-38). Durham and London: Duke UP.

Gusinde, M. (1951). Hombres primitivos en la Tierra del Fuego (de investigador a compañero de tribu). Sevilla: Escuela de Estudios Hispano-Americanos de Sevilla.

Alonso, M., Mestre, J., Rodríguez, M. y Triviños, G. (Eds.) (1989). Las plumas del colibrí. Quince años de poesía en Concepción (1973-1988). Estudio y Antología. Santiago de Chile: INPRODE-CESOC.

Merton, T. (1976). The Shoshoneans. Ishi Means Man (pp. 5-16). Greensboro, North Carolina: Unicorn Press.

Ostria, M. (1992). "De la tierra sin fuegos: los fuegos de la escritura.” Acta Literaria, 17, 171183.

Riveros, J. P. (1986). De la tierra sin fuegos. Serie Libros del Maitén 12. Concepción, Chile: Ediciones del Maitén.

Taussig, M. (1993). Mimesis and Alterity. A Particular History of the Senses. New York, London: Routledge.

Turner, V. (1974). Dramas, Fields and Metaphors. Simbolic Action in Human Society. Ithaca 
PEREGRINACIÓN Y COMUNIÓN EN DE LA TIERRA SIN FUEGOS DE JUAN PABLO RIVEROS

and London: Cornell UP.

Turner, V. (1969). The Ritual Process. Structure and Anti-Structure. Chicago: Aldine. 
